\title{
Anticipation Mechanism for Cold Wave: Forecast Based Financing a Case Study in the Peruvian Andes
}

\author{
Juan Bazo ${ }^{1,2 *}$, Coughlan de Perez ${ }^{1,3,4}$, Gerardo Jacome ${ }^{5}$, Kemper Mantilla ${ }^{6}$, \\ Mathieu Destrooper ${ }^{7}$ and Maarten Van Aalst ${ }^{1,4,8}$ \\ ${ }^{1}$ Red Cross Red Crescent Climate Centre, The Hague, Netherlands, ${ }^{2}$ Universidad Tecnológica de Perú (UTP), Lima, Peru, \\ ${ }^{3}$ Feinstein International Center, Friedman School of Nutrition Science and Policy, Tufts University, Boston, MA, United States, \\ ${ }^{4}$ International Research Institute for Climate and Society (IRI), New York, NY, United States, ${ }^{5}$ Cruz Roja Peruana, Lima, Peru, \\ ${ }^{6}$ Servicio Nacional de Meteorología e Hidrología del Perú (SENAMHI), Lima, Peru, ${ }^{7}$ German Red Cross, Berlin, Germany, \\ ${ }^{8}$ Faculty of Geo-Information Science and Earth Observation, University of Twente, Enschede, Netherlands
}

In June 2018, the Peruvian provinces of Arequipa and Puno in the southern Andean region were affected by heavy snowfall, which caused severe damage to people and livelihoods in several communities. Using the Forecast-based Financing approach, the Peruvian Red Cross implemented its pre-defined early action protocol before this event, after receiving an extreme snowfall warning (Level 4) from the Peruvian meteorological service. Here, we provide a case study of the approach and event itself, documenting the decision-making thresholds as well as the actions taken. This warning activated the thresholds established in the protocol, and Peruvian Red Cross prioritized 10 communities for pre-disaster support based on the forecasted severity of the event in combination with vulnerability and exposure information. The activation took place 2 days before the extreme snowfall in the communities, and the Red Cross distributed veterinary kits for 50 heads of cattle per family, tarpaulins, tool kits to install a temporary awning for alpacas to protect them from the cold wind and snow, protection kits for alpaca herders and warm clothing for children under five, pregnant women, the elderly, and people with chronic and infectious diseases in 430 highly vulnerable households. This article presents the results of a household survey following the impact of the extreme snowfall. We document the early actions taken by these communities to protect their livelihoods, health, and assets. The evaluation also presents descriptive statistics of household-level outcomes for households receiving pre-snowfall support and those that did not receive any intervention or only received post-disaster assistance. While most households took action to protect their assets, there were fewer extreme losses of alpaca herds reported in the communities who received the early support, and these communities also reported fewer adults suffering from respiratory illnesses. More in-depth research on this type of early action is necessary on a wider scale, especially to evaluate the utility of different support measures and the necessary quantity of support needed. This case study can inform government, civil society, and humanitarian actors of how early action is happening before disasters occur and provide a direction for further investment in research and practice to make use of hydro-meteorological forecasts for the benefit of the most vulnerable.

Keywords: forecast based financing, cold wave, anticipation, early actions, vulnerability, impact based forecasting, Peru 


\section{INTRODUCTION}

In the past decade, the Early Warning Early Action agenda has spurred investments in climate services, forecast information, and communication protocols worldwide. As a result, lives and livelihoods have been spared during hazardous events, particularly in cyclone-prone regions. In 2008, the International Federation of Red Cross Red Crescent Societies (IFRC) defined Early Warning Early Action as "routinely taking action before a disaster or health emergency happens, making full use of scientific information on all time scales." This is notable because it refers to responding systematically to a forecast, not to a disaster (IFRC, 2008). The World Disasters Report (IFRC, 2009) was dedicated to EWEA. Despite being in the spotlight, the full potential of early action has not yet been realized; many of the most devastating natural disasters in recent years were forecasted before they caused impact. Hence action could have been taken to reduce this impact. Yet the humanitarian system remains largely focused on response after the disaster and anticipatory actions rarely get funding.

The global community is determined to reverse this fact. Through the Sendai Framework for Disaster Risk Reduction, countries have committed to strengthen Early Warning Systems. In their Nationally Determined Contributions for the Paris Agreement, countries have committed to reduce the risks of extreme events. In addition, they have pledged to address disaster risk reduction as a cross-cutting necessity to achieve the Sustainable Development Goals. Forecast-based Financing is a mechanism that contributes to achieve these commitments by addressing the gaps between disaster risk finance, climate science and early action.

Forecast based financing (FbF) is an approach to accessing humanitarian funding for early action, based on weather forecasts and risk analysis, for the purpose of pre-emptive preparedness for extreme weather events (Coughlan de Perez et al., 2015). The aim of forecast-based preparedness is to anticipate disasters, prevent their effects as much as possible and reduce human suffering and loss of life. The $\mathrm{FbF}$ is based on the early warning early action approach (EWEA) for the humanitarian sector and has emerged from ongoing institutional learning on the implementation of early action based on early warnings (Coughlan de Perez et al., 2016; Costella et al., 2017; de la Poterie et al., 2018; Gros et al., 2019). Forecasts have been and are successfully used to provide early warnings for an increasing range of hazards at different timescales. The scope and magnitude of anticipatory actions taken vary depending on the forecast time frame and models used. Some hydrometeorological hazards can be predicted with relatively high accuracy and measures taken that can save lives or the livelihoods of vulnerable populations (Emerton et al., 2020; Lopez et al., 2020). With forecasts at different timescales, a range of risk reduction actions can be taken with seasonal, sub-seasonal and short-term lead times to prevent disaster losses in vulnerable communities in the near future (Tall, 2010; Bazo et al., 2019; MacLeod et al., 2021). In 2008, the International Federation of Red Cross and Red Crescent Societies (IFRC) West Africa regional office pre-positioned disaster management supplies in advance based on a seasonal forecast of above normal rainfall. This early action improved the availability of supplies by about 40 days when flooding occurred in the region (Braman et al., 2013).

In 2017, the Mongolian Red Cross carried out a successful intervention using the forecast based financing mechanism to minimize the impact of Duzd (drought combined with a harsh winter including snow) on pastorals households (Gros et al., 2021). Numerous successful examples of global early warning systems have been institutionalized in the humanitarian sector and are increasingly being developed; prominent examples include the Famine Early Warning Systems Network (Funk et al., 2019), Global Flood and Stream flow Forecasting (GloFAS), (Alfieri et al., 2013). These are increasingly being incorporated into early action protocols developed by national societies and national hydro-meteorological services (Jjemba et al., 2018).

One of the main obstacles to anticipatory humanitarian action based on forecasts has been funding. Normally humanitarians must wait for emergency declarations to act immediately after a disaster has struck (Coughlan de Perez et al., 2015). A new funding mechanism within the International Federation of the Red Cross allows for the automatic release of funds based on a forecast of an extreme hydro-meteorological events to implement predefined actions through an Early Action Protocol (EAP).

This case study documents one of the first EAPs tested as part of the new funding mechanism, providing a description of the actions and reported outcomes to inform future programming. In the EAP, all stakeholders are involved (national Red Cross society, national hydro-meteorological service, disaster management office, among other institutions) in which they pre-agree on a set of actions, triggers, and communication channels. In this way, decisions are automatic once a disaster of a certain magnitude is predicted and forecasts above a certain threshold, allowing the national Red Cross society to make the best use of the limited lead time to take early action as described in the EAP (IFRC, 2018). Peru is one of the most disaster-prone countries in the Latin American region and very vulnerable to climate change due to its geographical features and high vulnerability. This includes earthquakes, El Niño induced floods in the coastal and northern areas of the country, floods in the Amazonian lowlands and severe cold waves in the southern mountains and landslides. For the most relevant hazards, early warning system efforts are still under development, including the improvement of regional climate services and new early warning systems to address increasing risks due to climate variability and climate change (Emmer and Vil'imek, 2014; Rosas et al., 2016). Based on the high recurrence of extreme weather events, Peru was one of the first countries to implement the $\mathrm{FbF}$ mechanism and one of the first to develop a cold wave early action protocol (IFRC, 2018). In the Andean region of Peru, in areas located above 3,200 $\mathrm{m}$ above sea level, the highest number of days with meteorological frosts occur mainly between May and September (cold season), with a higher incidence between June and July; in the central highlands between May and August, with a higher incidence in June; and in the northern highlands the maximum occurs between July and November (Alarcón and Trebejo, 2010). However, some localities located above $4,000 \mathrm{~m}$ above sea level in the departments of Arequipa, Moquegua, Huancavelica, Cusco, Tacna and Puno, 
climatically present meteorological frosts during the year, and are more pronounced in autumn, winter, and spring (permanent frosts). Alpaca farmers' families in the high Andean region are the most affected by cold waves as they regularly settle in remote areas where they have the space to raise and feed their animals (Oliver-Smith, 2014). Therefore, cold waves severely threaten the health and livelihoods of whole communities across the high Andean region (Sanchez, 2018). Populations in these regions have developed a high level of resilience and have adapted their livelihood strategies to such climatic conditions (Ponce, 2020). However, in some years the magnitude of cold waves far exceeds normal conditions and the adaptive capacity of communities, causing a considerable impact on people's health and livelihoods. For example, important interventions and Disaster Relief Emergency Funds (DREF) were activated by the Peruvian Red Cross in 2003 and 2007 to assist communities affected by extreme cold, as 65,300 animals died in 2007 (IFRC, 2003, 2008).

This case study from Peru is part of the German Federal Foreign Office's Action Plan for Humanitarian Adaptation to Climate Change. It was implemented in the pilot phase of the FbF during a first phase in which the project countries (Peru, Bangladesh, and Mozambique) focused on small-scale interventions to test and refine the approach. In the case of Peru, it was led by the Red Cross Red Crescent Society of Peru, with support from the German Red Cross and technical assistance from the Red Cross Red Crescent Climate Center (GRC, 2017).

This case study examines a specific FbF activation in the Peruvian Andes, cold waves and snowfalls are the third most frequent hazard, causing health problems for the vulnerable population and severe losses and damages to livelihoods. In general, the temperature starts dropping in Peru in April and extreme low temperatures occur between June and August. Disasters can occur due to isolated events of cold or snowfall; however, these are generally produced when both extreme cold and snowfall coincide, which reduces pasture availability and in turn can increase herd mortality. Once herds go below given thresholds, they can become non-viable, leading to what some researchers call a poverty trap (Barrett et al., 2008) and illustrating the importance of mechanisms that support herd retention for resilience. Often as an effect of the reduction of herd size due to cold wave/ snowfall, herders may give up their pastoral livelihoods entirely and undertake destitution migration into urban areas (Sperling et al., 2008; Koubi et al., 2016) which in turn presents challenges for development. In recent decades, there are indications of increasing intensities of cold wave (PCM, 2019), leading to a heightened urgency to develop effective DRR tools for this phenomenon.

While it is highly desirable to integrate forecast-based action mechanisms with institutionalized programs in the Peruvian government, this work is still in the early stages. The country does have however several significant social protections one of the most important of these is the multisectoral committee for frosts and cold spells. This program has been established since 2012 (PCM, 2019), and the interventions financed were mainly oriented toward preparedness and/or response actions to possible impacts of frost, for example, the provision of shelter kits. In other words, interventions aimed at reducing risks to the health and livelihoods of the population exposed to frost and extreme cold.

In this case study the main goal is to assess the effectiveness of Forecast-based Financing distributions in helping vulnerable populations to take early preparedness measures, and to prevent and reduce the negative impacts of natural disasters on their health, well-being, assets, and livelihoods. The expected benefits of forecast-based in advance cold wave in the Peruvian Andes were identified based on communitylevel consultations, a literature review, and consultations with Peruvian Red Cross staff and volunteers. In this paper, we test the hypotheses that households who receive forecast based humanitarian aids before the cold wave are better able to mobilize areas safer when needed, Due to the smallness of the intervention and the data analysis, only limited differences were observed between the group of intervention and nonintervention communities were identified. It was reported that the intervention communities had less loss of livelihoods than the comparison group. The same was reflected in the health impact, suffer less from diseases in the aftermath of the cold wave, and resume productive activities sooner than non-FbFassisted households.

The article offers a case study through analyzing the results of a quasi-experimental study evaluating the FbF intervention. The following sections present information on the intervention and study methodology, and the study findings, including on the intervention's impact as well as variation in the perceived timing of when assistance was received. The article concludes with a discussion on lessons learnt and proposed next steps in both research and practice.

\section{MATERIALS AND METHODS \\ FbF Intervention Context and Overview}

Peru is divided into three climatic zones: the Amazon rainforest in the east, the Pacific coast in the west and the highlands in the center, from north to south. Most Peruvians classified as poor live in the highlands. Lower temperatures are frequent in this part of the country and have important economic consequences.

According to official statistics from the Peruvian Civil Defense Institute, between 2003 and 2019, 7,361 cold waves and snowfall events were reported. These events are basically concentrated in the central and southern departments of Peru in areas above 3,500 meters above sea level Figure 1. However, cold waves and snowfall can pose a significant threat to the health and livelihoods of people living in the high altitudes of the Peruvian Andes (Huggel et al., 2008). During the most stressful years for people and their livelihoods, such as when cold waves occur, vulnerable populations do not have sufficient access to health clinics can run short of feed and supplies for animal care. Access to necessary supplies is limited because the areas where these populations are located are distant from towns where they can have access to health and animal supplies. In critical years this can lead to increased mortality in both people and their animals, which can 


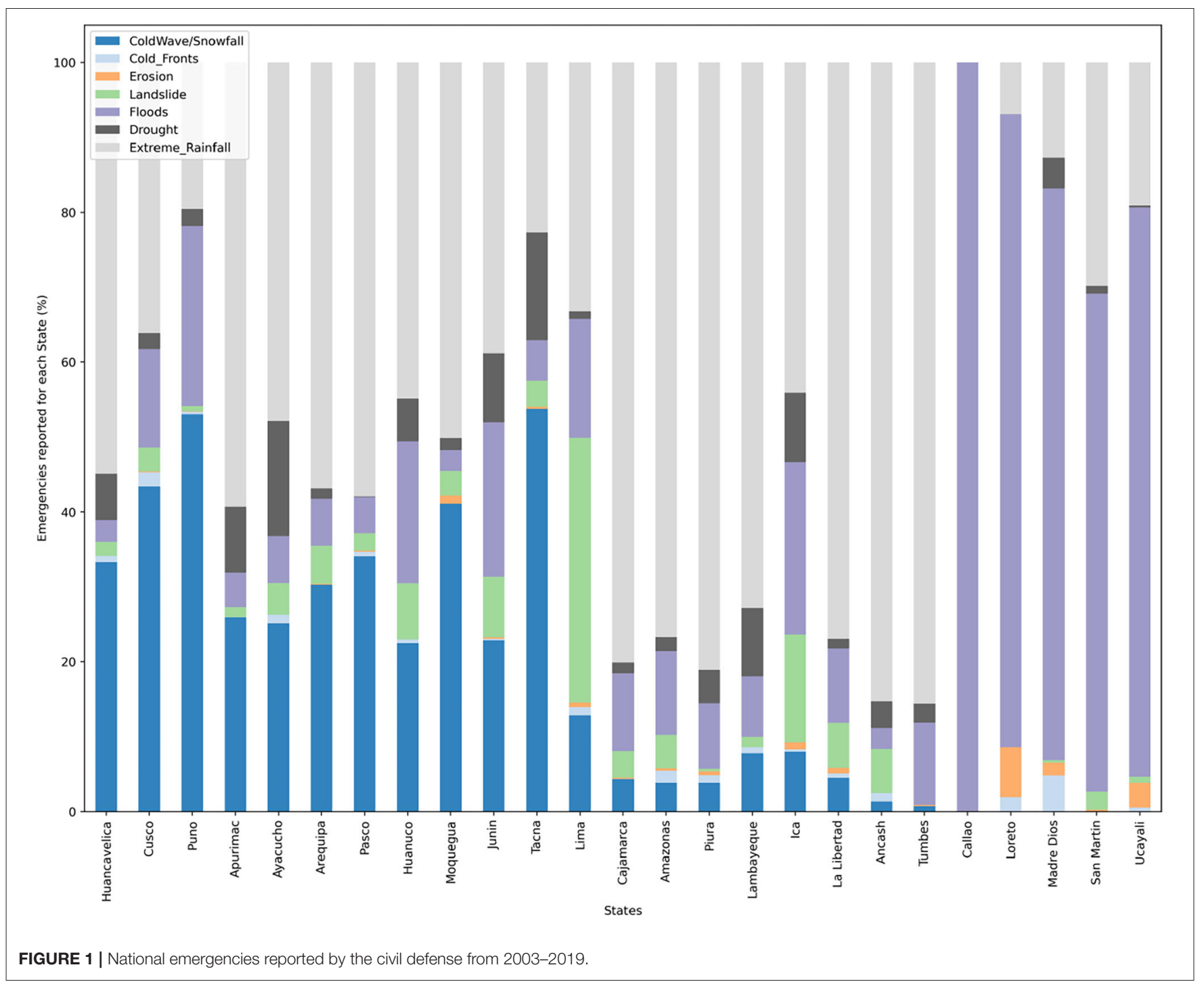

have huge implications for the lives and livelihoods of the herders (Otto et al., 2018; Staübli et al., 2018).

In previous years, Peruvian government response agencies and especially the Peruvian Red Cross have responded to disasters caused by cold waves and snowfall through the Disaster Relief Emergency Fund (DREF) of the International Federation of Red Cross and Red Crescent Societies (IFRC) and through other humanitarian response and funding mechanisms. In 2003, a severe cold wave caused severe impacts in the southern Andean region of Peru, killing dozens of elderly people and children under 5 years of age, as well as a large loss of livelihoods, mainly South American camelids (IFRC, 2003). Similar events have occurred in these areas $(2013,2015,2016)$, where poverty is widespread, with respiratory diseases being the main causes of death (IFRC, 2013; Staübli et al., 2018).

The Forecast-based Financing pilot was established to reduce the impact of these extreme events, led by the Peruvian Red
Cross. Humanitarian funds can now be released for preagreed humanitarian activities based on information from hydro-meteorological forecasts and risk analysis. Funds are automatically allocated when a certain threshold is reached so that early actions can be carried out quickly and efficiently before a disaster occurs, as soon as weather or hydrological forecasts combined with risk elements indicate a high probability of a cold wave/snowfall event in communities in the southern Peruvian Andes that could severely affect people, their assets and/or their livelihoods. In 2018 the Peruvian Red Cross Society (PRC) established a FbF mechanism and developed an Early action protocol (EAP) to help herder households cope with the anticipated impacts of extreme cold and snowfall based on forecast warning information and the risks maps (Impact based forecast methodology). Nine indicators establish the risk of extreme cold and snowfall, including snowfall frequency, temperatures low percentiles, pneumonia rate, altitude, population above 3,500 above sea level, poverty 

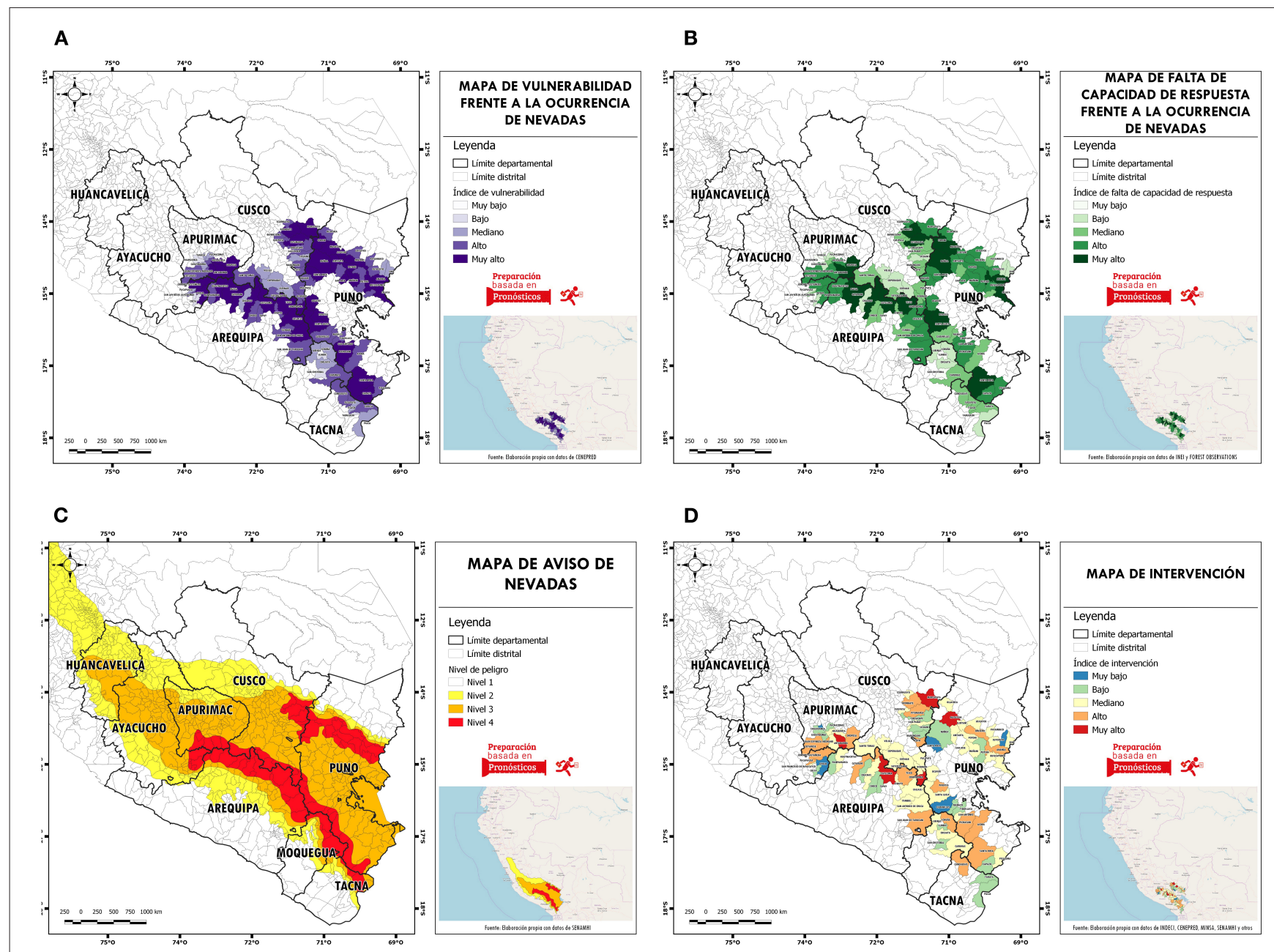

FIGURE 2 | Maps of risk and hazard elements used to determine the intervention map (impact-based forecasting), (A) Snowfall vulnerability map, (B) Lack of response capacity map, (C) Snowfall forecast map, (D) Intervention map.

TABLE 1 | Interventions and comparison communities.

\begin{tabular}{lllc}
\hline Status & Location & Indicator & Number \\
\hline Intervention communities & Caylloma & Adults over 65 years old & 13 \\
& & Children under 5 years old & 10 \\
Comparison communities & Caylloma & Adults over 65 years old & 12 \\
& & Children under 5 years old & 15 \\
Intervention communities & \multirow{2}{*}{ Santa Lucia } & Adults over 65 years old & 6 \\
& & Children under 5 years old & 9 \\
Comparison communities & Santa Lucia & Adults over 65 years old & 8 \\
& & Children under 5 years old & 10 \\
\hline
\end{tabular}

index, alpaca population, elderly population above 65 years old and children under 5 years old (IFRC, 2018). This early action protocol focuses on cold waves and snowfall that typically occur in the southern Andean region of Peru during the coldest months (between May and October). Early actions can be activated based on a 5-day "lead time" weather forecast, which is the time between the issue of a forecast and the occurrence of the predicted event, with a level 4 warning (the highest on the warning scale) corresponding to a $60-80 \%$ probability of having a high impact snowfall event $(20 \mathrm{~mm}$ of snow) per more than 4 consecutive days with temperatures below 5th percentile, the forecast came from the Peruvian Hydrological and Meteorological Service (SENAMHI).

\section{Case Study Triggering of Forecast-Based Humanitarian Distributions During the 2018 Cold Wave/Snowfall in Peru}

At the beginning of May 2018, the cold season started with some light to moderate snowfall events beginning to hit the high Andean regions of southern Peru. On 31 May, the National Meteorological and Hydrological Service of Peru (SENAMHI) issued a level 4 meteorological warning for snowfall (warning No. 058) with a lead time of 96 hours and reaching values of $20 \mathrm{~mm} /$ day snow and widespread snowfall. The CRP decided to activate the Cold wave/Snowfall EAP with the information 


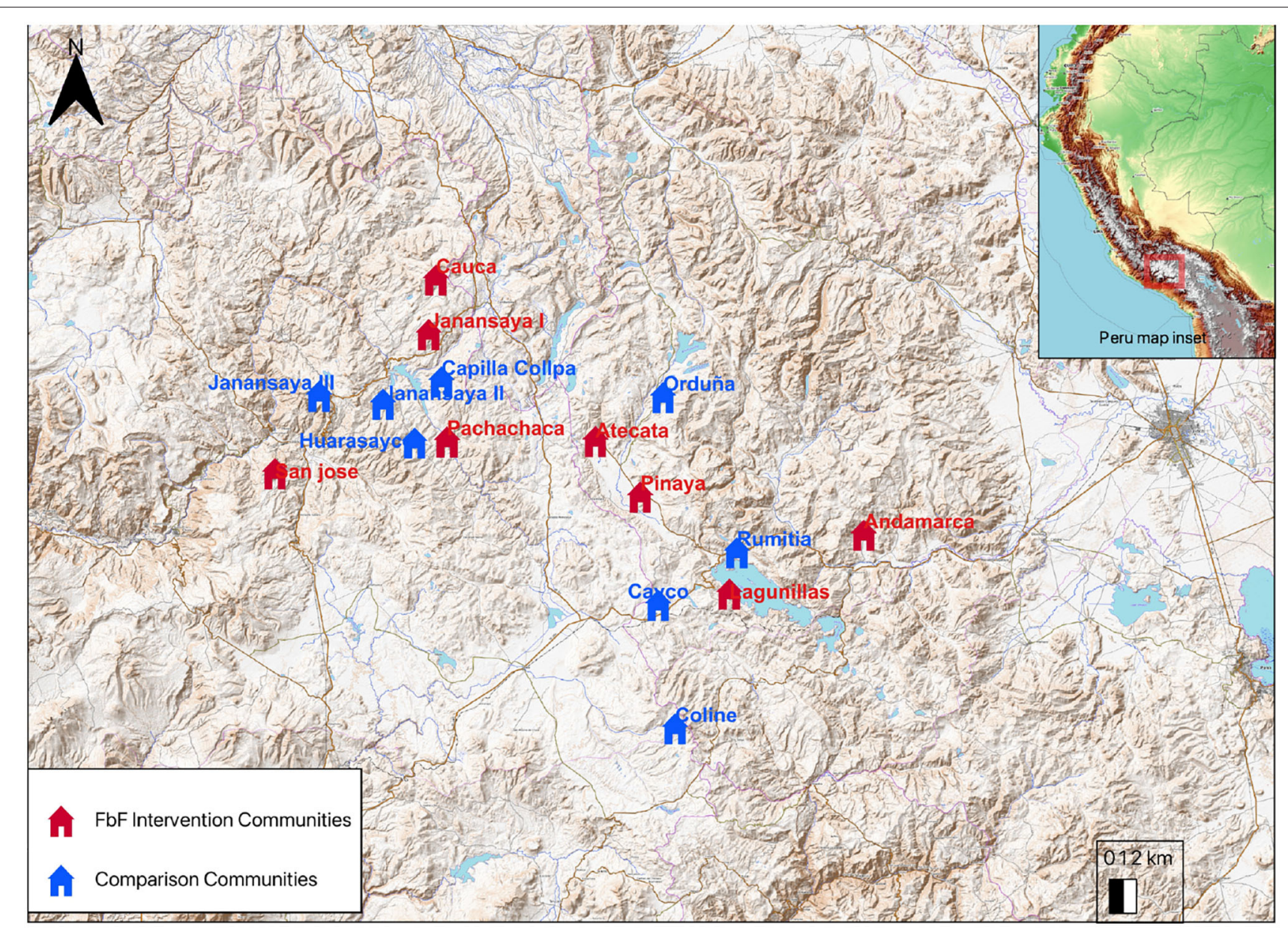

FIGURE 3 | Location of intervention and comparison communities in the districts of Arequipa (Caylloma) and Puno (Santa Lucia).

received from SENAMHI and started to deploy its actions from that point forward. Pre-disaster support was provided two communities in two districts in southern Peru in the departments of Arequipa (locality of Caylloma) and Puno (Santa Lucia) where, after using an impact model (Impact-based forecasting approach is the basis of the FbF trigger methodology. The trigger is the degree of forecast loss and damage (human, livelihoods, infrastructure, environment etc.), or in other words the degree of humanitarian impact, of an extreme event, that would initiate action, (GRC, 2020). Intervention communities were selected that represented the highest risk when the following variables were combined: 5-day forecast of extreme cold and snowfall, pneumonia rate, altitude, population above 3,500 above sea level, poverty index, alpaca population, elderly population above 65 years old and children under 5 years old. Two communities were selected that had the highest value in risk index of these factor (see Figure 2). Humanitarian distribution began 3 days before the snow hit the identified communities (May 2, 2018). The Red Cross distributed: veterinary kits for 50 livestock per family, two tarpaulins $(4 \times 6$ meters waterproof) with a toolkit (hammer, nails, ropes, saw, multi-purpose gloves) to set up temporary shelter for the alpacas to protect them from the cold wind and
TABLE 2 | Common early actions taken by alpaca-herding communities before and during a cold wave/snowfall event in 2018 .

\section{Action}

Percent

Antiparasitic, antibiotic and vitamins given to livestock

Protect livestock sheds using tarps

$22 \%$

Migrate to lower-altitude areas

$19 \%$

Take animals out earlier

$9 \%$

snow, protection kit for the alpaca herders (rubber poncho, sunglasses, anti-cut gloves, boots) for snowfall, warm clothes for children under 5 years of age, pregnant women, the elderly and people with chronic and infectious diseases (jackets, gloves and socks), tarpaulin $(4 \times 6$ meters $)$ to improve the insulation of houses in 10 communities in the most at risk districts identified.

\section{Beneficiary Eligibility Criteria}

The eligibility of households (Table 1) to be included as beneficiaries of the Peruvian Red Cross intervention was assessed based on a vulnerability score for each household using some pre-established criteria in the EAP such as the number of 
household members who are children under 5 years old, adults over 65 years old, with disabilities, pregnant women, and people with chronic diseases, poverty index. Families were excluded if they were on the list of beneficiary households for a multisectoral plan of frost and cold weather events that is carried out annually throughout the Andean region of Peru by the Peruvian government to minimize the impact of the cold season in vulnerable households are detailed, however this plan has other criteria quite different from those in this EAP (PCM, 2019).

\section{Study Design}

The FbF activation in June 2018, related to cold waves and snowfall, was activated in the districts of Caylloma (Arequipa) and Santa Lucia (Puno), where impact-based forecasting indicated that they were the highest risk districts. This intervention, carried out by the Peruvian Red Cross, was accompanied by an empirical and quasi-experimental study to estimate the impact of the provision of humanitarian assistance based on impact on the target population of vulnerable households in both districts at high risk of impact. The evaluation was intended to test the FBF mechanism's assumptions about the expected benefits of humanitarian aid distribution, as described in the introduction. The FbF funds had been used to assist eight high-risk communities in both districts. For the purposes of this study, eight nearby communities' Figure 3. With a similar vulnerability profile to the intervened communities were selected to serve as "comparison communities." In the intervention communities, the 430 most vulnerable households that received provision-based humanitarian assistance constitute the intervention group of the study. In the control communities, the same vulnerability criteria described in section Case Study were used to select the most vulnerable households for inclusion in the survey sample. The intervention and comparison communities were interviewed during a survey conducted at the end of June 2018, $\sim 1$ month after the event ended. A total of 166 completed responses were collected, 79 (or 47.6\%) from intervention households and 87 (52.4\%) from comparison households. Surveys were conducted during 22-24 June 2018; Peruvian Red Cross volunteers and staff were trained and updated on a structured questionnaire and deployed in the field using Open Data Kit (ODK-build) as a mobile data entry and management platform. Quantitative and open-response data were collected through 18 questions for each household.

\section{RESULTS AND DISCUSSION}

This study explores which actions were taken to prepare for and manage the extreme cold/snowfall, and the extent of the impacts on alpaca herding households. In both cases, we examine whether there are significant differences between the intervention and comparison households. When it comes to early actions, the alpine communities reported a number of actions that were taken before or during the extreme cold/snowfall event. Most people reported receiving an early warning about the event. The veterinary kits per family for delivery and dosage before cold waves contained internal and external antiparasitic, antibiotics, vitamins and complementary accessories such as syringes, needles, iodine alcohol, cotton wool, in order to prevent animal morbidity and mortality and increase milk, wool and meat production yields. Many shepherds move their livestock to lower altitudes after receiving a warning of cold waves, with this action they avoid that their animals suffer the impact of the cold temperature in the higher altitude areas, however, to do this they need permission from other communities established in lower altitudes and often the shepherds must pay a fee to establish in these areas. The most common actions are listed below (Table 2), alongside the percent of respondents who reported taking that action (combined comparison and intervention groups).

To assess the effects of providing forecast-based financing on the livelihoods and well-being of herder households, a quasi-experimental study design was developed by Peruvian Red Cross to collect representative sample survey data from FbF beneficiaries and comparison households that were equally vulnerable and exposed to the same extreme winter conditions. The quasi-experimental design allowed the researchers to compare the effects of $\mathrm{FbF}$ on the experience and socio-economic well-being of beneficiary households against the counterfactual of comparable households who did not receive $\mathrm{FbF}$ assistance. The same eligibility criteria were used as for the $\mathrm{FbF}$ intervention to select a random sample of 70 beneficiaries (out of 430 reached support) and 96 comparison households. Experimental and quasi-experimental research designs have been widely used to assess the impacts (Bastagli et al., 2019) and other development interventions.

The intervention targeted the most vulnerable households based on the information obtained in the community consultations (Table 1), we did not find a significant difference between the intervention and comparison households with respect to the vulnerable population (older adults over 65 and children under 5 years of age). Given that the communities did not present large differences, it was decided to use a statistical methodology, the Kolmogorov-Smirnov test, which is a non-parametric test of the equality of continuous and unidimensional probability distributions that can be used to compare a sample with a reference probability distribution, or to compare two samples. In our case this test helped us to make a comparison between the samples of the beneficiary and comparison communities.

Of these common actions, the only action that was significantly different between the intervention and comparison groups was the action to migrate to \% of the comparison group migrated to lower-altitude areas, while only $11 \%$ of the intervention group did so. This is significant with a $p$-value of 0.01 using a Chi-squared test. It is possible that herders find migration a time and resource-heavy option to protect their livestock, and therefore those who received early support might have decided to remain in their locations with increased confidence of their herds surviving the event. Other actions that were reported by one or more households were:

- Saving food and water

- Drinking natural herbs (e.g., anise seed)

- Putting coats and jackets on babies 


\section{Number of Alpaca Reported Affected}

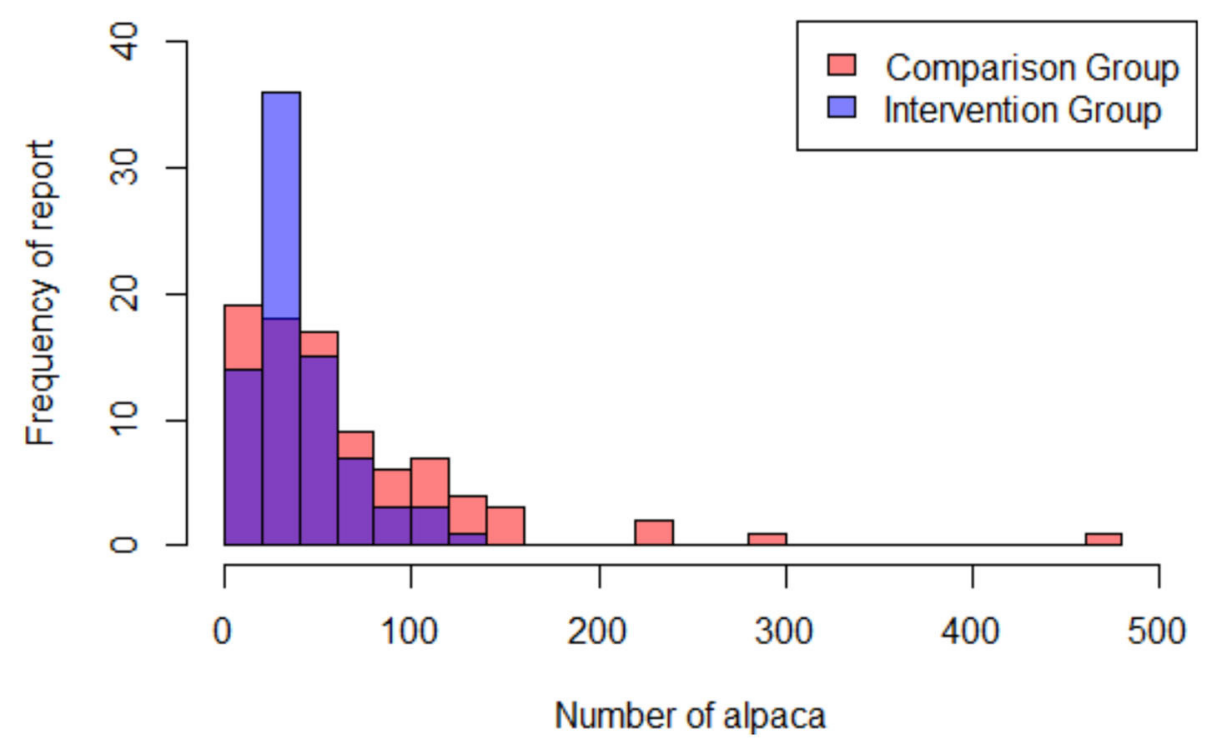

FIGURE 4 | How many alpacas were reported by each household as affected by the extreme event.

- Cleaning animal shelters

- Using blankets.

While we were not able to detect a difference in the number of people taking early action between the intervention and comparison groups, it is possible that the groups did differ in terms of the extent of their early action. Further research is needed to understand whether early supports helped people protect greater numbers of alpaca, for example. Both intervention and comparison groups reported negative impacts from the extreme event, with the intervention group reporting fewer extreme losses or impacts. In terms of effects on their alpaca herds, households reported that some alpaca died during or shortly after the event itself. Others suffered from respiratory problems or diarrhea. To create a larger statistical sample, we combined these outcomes into one variable of "Alpaca impact," simply summing the number of animals, adults as well as young alpaca, who fell into each category. This indicated the number of impacted alpacas per household in this event. As illustrated in Figure 4 the number of alpacas affected in the intervention group, who received the early humanitarian assistance, tended to be less extreme than the number affected in the comparison group. There were fewer high losses, e.g., over 75 alpacas lost per household, in the intervention group. A KolmogorovSmirnov Test comparing the two distributions indicates that the two are significantly different from each other, with a $p$ value of 0.02. In terms of human impacts, the post-event survey asked about respiratory ailments in adults as well. As illustrated in Figure 5, the number of adults per household reporting respiratory ailments tended to be fewer than in the intervention group. Given the small sample size, this is a tentative finding and would need to be researched further. A chi-square test for categorical data results in a $p$-value of 0.08 . The intervention group also reported spending less on medical care, but this was not significantly different from the comparison group.

The results show that the $\mathrm{FbF}$ intervention in Peru was successful in identifying the most vulnerable households, and that the survey was relatively successful in identifying comparable groups of similar herder households that did not receive $\mathrm{FbF}$ assistance. The assistance appears to have had a statistically significant effect in helping beneficiaries reduce mortality of alpacas, one of the most valuable animals (in the Peruvian Andes), by $\sim 30 \%$ compared to households that did not receive the $\mathrm{FbF}$ intervention. Although after heavy snowfall herders can continue with their livelihoods without significant disruption. In the long term, interventions such as the $\mathrm{FbF}$ examined here can help cushion the negative impact on herders' livelihoods during years of high risk of extreme events. This on a larger scale could reduce the level of impact on livelihoods and reduce the number of livestock herders may lose, which directly affects their economy. The need to improve early warning, early action, anticipation of disasters and crises, improved preparedness and investment in risk reduction has been recognized in several global policy processes and outcome documents such as the Sendai Framework for Disaster Risk Reduction, the Sustainable Development Goals, the Paris Agreement, the World Humanitarian Summit and the Agenda for Humanity, as well as in several humanitarian resolutions of the United Nations General Assembly and the Peruvian government is part of it. Since 2012, the Peruvian government has implemented an annual Multisectoral Plan for cold wave in which it has had a reactive management approach where it has sought to propose risk reduction and preparedness interventions for an 


\section{Adults with Respiratory Ailments}

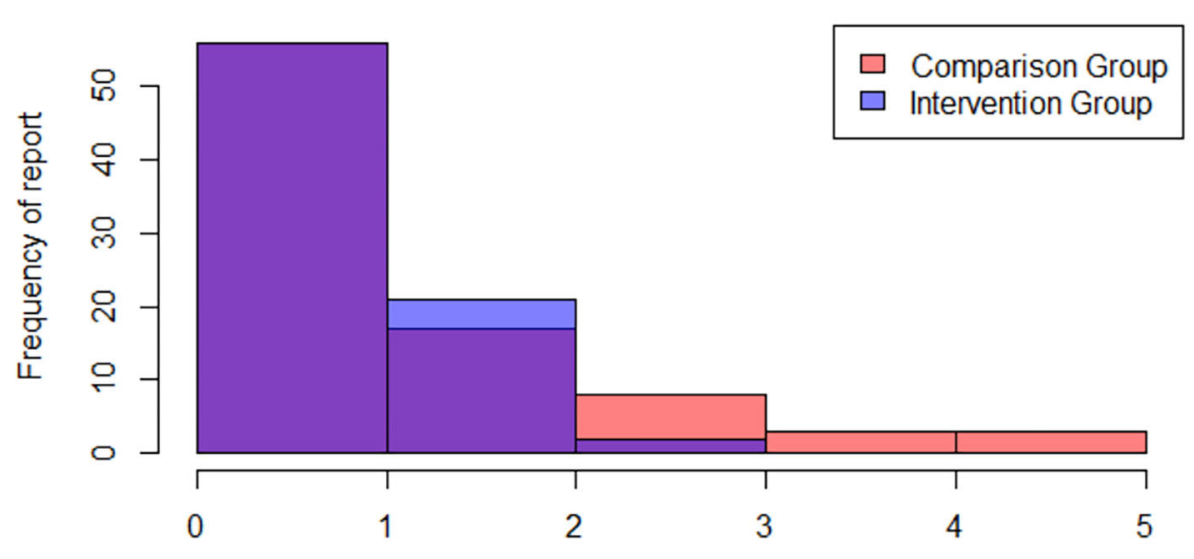

Number of household members

\section{Spending for sickness}

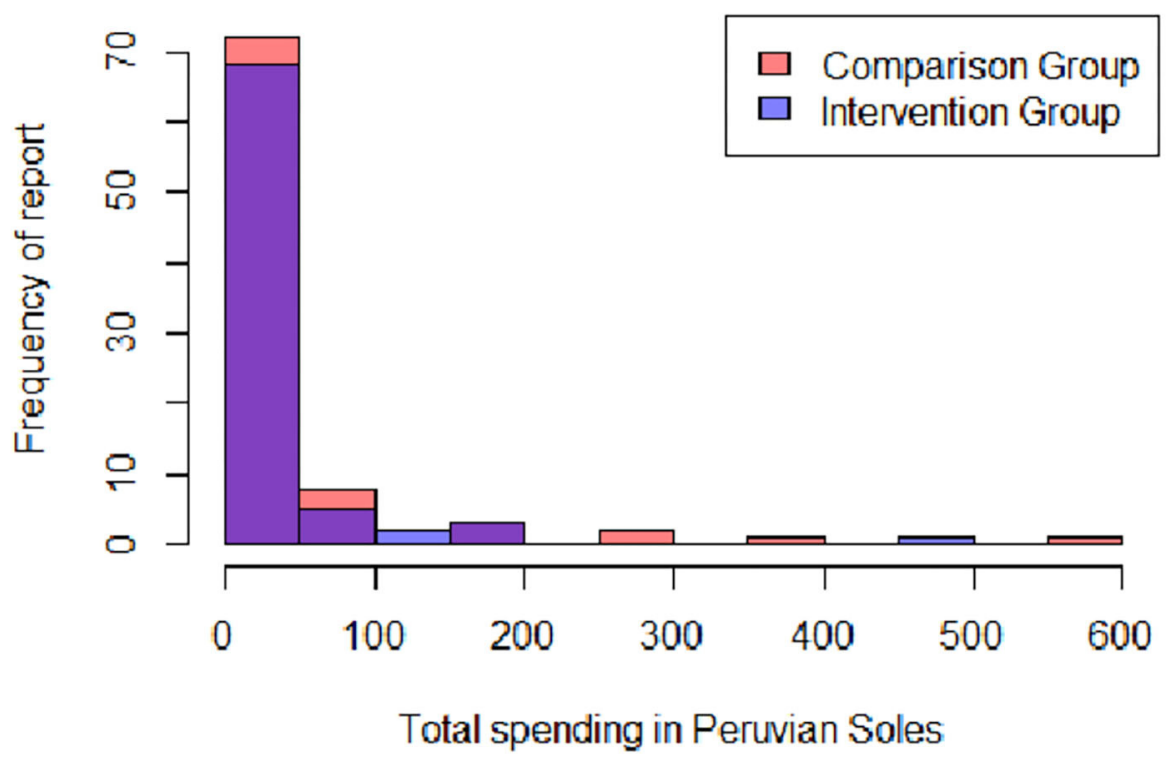

FIGURE 5 | Reported numbers of adults with respiratory ailments and amount spent on sicknesses in the intervention and control groups.

optimal response to potential impacts. The implementation of FbF supports to fulfill the commitments made by states in these processes. Establishing $\mathrm{FbF}$ funding mechanisms, designing scientific thresholds to trigger early action, and commit to implement EAPs will improve humanitarian assistance and will make disaster risk reduction and climate change adaptation more cost-effective and efficient. It is a powerful tool to avert human suffering because of extreme weather disasters. An institutionalization of the FbF mechanism within the national risk system in Peru could contribute to triggering early actions in case of extreme weather events that could minimize losses of large numbers of livestock, while increasing the resilience of households in the high Andean areas of Peru.

\section{CONCLUSIONS}

Cold waves are a recurrent atmospheric phenomenon in the high Andean zones of Peru, generally located more than 3,500 m 
above sea level, where the ambient temperature drops to levels below $0^{\circ} \mathrm{C}$, with greater intensity during the period from May to September. In some extreme years, these cold snaps have a great impact on the population and their livelihoods. From a meteorological point of view, numerous studies have focused on cold air intrusions from the south that extend toward the equator and reach the Bolivian Amazon and southern Peru, causing sudden and severe temperature drops of up to $10^{\circ} \mathrm{C}$ in a few hours, affecting people, livestock, and crops (Ronchail, 1989; Marengo et al., 1997; Garreaud, 1999; Espinoza et al., 2013b). However, few have described cold waves in the high Andes. (Espinoza et al., 2013a), proposed a cause by cold air advection associated with equatorward propagation of midlatitude Ross by wave trains eastward from the Andes during the night or early morning. The equatorward propagation of cold, dry air masses reduces cloudiness and inhibits moisture inflow, convective activity and thus cloud formation. Trasmonte et al. (2008) documented that the local population of the central Peruvian Andes assumes that incursions of cold and dry air masses represent the main physical mechanism for generating cold episodes. In contrast, Montes de Oca (1995) noted that cold waves sometimes generate sporadic solid precipitation (snow) events during their propagation along the eastern slope of the central Bolivian Andes. Likewise, Hurley et al. (2015) documented that about $70 \%$ of the total snow accumulation at the Quelccaya Ice Cap, located in the Peruvian Andes at 5,680 m altitude, is associated with cold air incursions.

The population of these localities are normally vulnerable to this atmospheric phenomenon, due to their socio-economic condition and geographical location, among other factors. Cold waves cause material damage, as well as damage to people's health and agricultural activity, affecting the economy of many families People of vulnerable age live in these areas, and that most of the people in these areas do not have health insurance and their income is basically focused on livestock farming, and that most of the houses are made of adobe with stone and mud (INEI, 2019). In 2003, 62 people were reported dead (IFRC, 2003), while in 2007, 48 deaths of children were reported (IFRC, 2008). The deaths of people and children are not only due to the cold wave, but also to the lack of health facilities close to the communities.

In these areas, heating systems are rarely available in homes, which often causes neonates and children under 5 years of age to fall ill due to hypothermia and acute respiratory problems. In addition to the deaths of people, there are other adverse impacts of the cold wave in the southern Peruvian Andean region. The operations of schools and people's daily lives and livelihoods are often severely disrupted by cold waves, especially vulnerable people such as children, the elderly and pregnant women with low-income groups and pastorals are the most affected. Cold waves have been found to be a risk factor for diseases such as respiratory diseases, cardiovascular diseases, viral influenza, and rotavirus infection (Pradhan et al., 2019).

In the framework of $\mathrm{FbF}$, effective early actions and timely preparedness for response measures protect development gains in the window of opportunity between a forecast and a potential disaster. This requires a coordinated system in which the government and its partners agree beforehand to allocate funding to protect its population, in sectors such as education, health, infrastructure and others. It is here where $\mathrm{FbF}$ is not only a risk reduction and preparedness strategy but contributes to the achievement of the Sustainable Development Goals.

Early warning systems and Forecast-based Financing is one mechanism to support people who are facing cold waves in Peru. Based on the results from this case study, early support is possible in the high Andes with existing weather forecasts, and there are tentative indications of benefits to the population. More research is needed as to how much support is most beneficial, to whom, and when. This case study has helped outline the questions needed for further research, such as why people would choose to migrate or not, and what kind of tailored support should be given to people who are able to migrate to lower altitudes and those who are not. Further research is also needed on health outcomes, including the appropriate investments in healthcare facilities as well as early action interventions that can best help people avoid negative health impacts from extreme weather events. Herders in the Peruvian Andes do take early action to prepare for extreme cold and snowfall events, to protect their health and their assets. Greater support to these populations in the form of long-term investments as well as short-term forecastbased financing has the potential to help people avoid negative impacts during extreme events. This case study can be an example for other countries and humanitarian responders working with pastorals populations in relation to complex hazards, both in terms of establishing impact-based forecasting and warnings to communicate information to enable people at risk to make effective decisions to protect themselves against the impact of expected extreme weather or climate events.

\section{DATA AVAILABILITY STATEMENT}

The original contributions presented in the study are included in the article/supplementary materials, further inquiries can be directed to the corresponding author.

\section{AUTHOR CONTRIBUTIONS}

JB and CP were responsible for the conceptualization, developed and analyzed the data with inputs from MA, and prepared the manuscript with editing contributions from all authors. GJ and KM facilitated access to project resources (including datasets and documents). MD provided contextual information and responsible for fund acquisition. All authors contributed to the article and approved the submitted version.

\section{FUNDING}

This work was supported by the German Federal Foreign Office, under the Action Plan of the Federal Foreign Office for humanitarian adaptation to climate change.

\section{ACKNOWLEDGMENTS}

The authors would like to thank the Peruvian Red Cross Society staff and volunteers implemented the intervention, supported 
the data collection underlying this study, and work tirelessly to assist vulnerable populations in the Peruvian Andes with relief humanitarian aids efforts. We thank colleagues from Peruvian Meteorological and Hydrological Service (SENAMHI) for your support and inputs. The authors also gratefully

\section{REFERENCES}

Alarcón, C., and Trebejo, I. (2010) Atlas de Heladas del Perú. SENAMHI. Available online at: https://hdl.handle.net/20.500.12542/359

Alfieri, L., Burek, P., Dutra, E., Krzeminski, B., Muraro, D., Thielen, J., et al. (2013). Glofas-global ensemble streamflow forecasting and flood early warning. Hydrol. Earth Syst. Sci. 17, 1161-1175. doi: 10.5194/hess-17-11 61-2013

Barrett, C., Carter, M., and Ikegami, M. (2008). Poverty traps and social protection, No 42752, Social Protection Discussion Papers and Notes. The World Bank. Available online at: https://EconPapers.repec.org/RePEc:wbk:hdnspu:42752

Bastagli, F., Hagen-Zanker, J., Harman, L., Barca, V., Sturge, G., and Schmidt, T. (2019). The impact of cash transfers: a review of the evidence from low-and middle-income countries. J. Soc. Policy 48, 569-594. doi: $10.1017 /$ S0047279418000715

Bazo, J., Singh, R., Destrooper, M., and de Perez, E. C. (2019). "Pilot experiences in using seamless forecasts for early action: The "ready-set-go!" approach in the red cross," in Sub-Seasonal to Seasonal Prediction, eds A. W. Robertson and F. Vitart (Elsevier), 387-398. doi: 10.1016/B978-0-12-811714-9.00018-8

Braman, L. M., van Aalst, M. K., Mason, S. J., Suarez, P., Ait-Chellouche, Y., and Tall, A. (2013). Climate forecasts in disaster management: red cross flood operations in west africa, 2008. Disasters 37, 144-164. doi: 10.1111/j.1467-7717.2012.01297.x

Costella, C., Jaime, C., Arrighi, J., de Perez, E. C., Suarez, P., and van Aalst, M. (2017). Scalable and sustainable: How to build anticipatory capacity into social protection systems. IDS Bull. 48, 31-46. doi: 10.19088/1968-2017.151

Coughlan de Perez, E., van den Hurk, B., Van Aalst, M., Jongman, B., Klose, T., and Suarez, P. (2015). Forecast-based financing: an approach for catalyzing humanitarian action based on extreme weather and climate forecasts. Nat. Hazards Earth Syst. Sci. 15, 895-904. doi: 10.5194/nhess-15-895-2015

Coughlan de Perez, E., van den Hurk, B., van Aalst, M. K., Amuron, I., Bamanya, D., Hauser, T., et al. (2016). Action-based flood forecasting for triggering humanitarian action. Hydrol. Earth Syst. Sci. 20, 3549-3560. doi: 10.5194/hess-20-3549-2016

de la Poterie, A. S. T., Jjemba, W. E., Singh, R., de Perez, E. C., Costella, C. V., and Arrighi, J. (2018). Understanding the use of 2015-2016 el nin $\sim_{0}$ forecasts in shaping early humanitarian action in eastern and southern africa. Int. J. Disaster Risk Reduct. 30, 81-94. doi: 10.1016/j.ijdrr.2018.02.025

Emerton, R., Cloke, H., Ficchi, A., Hawker, L., de Wit, S., Speight, L., et al. (2020). Emergency flood bulletins for cyclones idai and kenneth: a critical evaluation of the use of global flood forecasts for international humanitarian preparedness and response. Int. J. Disaster Risk Reduct. 50:101811. doi: $10.1016 /$ j.ijdrr.2020.101811

Emmer, A., and Vil'imek, V. (2014). New method for assessing the susceptibility of glacial lakes to outburst floods in the cordillera blanca, peru. Hydrol. Earth Syst. Sci. 18, 3461-3479. doi: 10.5194/hess-18-3461-2014

Espinoza, J. C., Ronchail, J., Frappart, F., Lavado, W., Santini, W., and Guyot, J. L. (2013a). The major floods in the Amazonas River and tributaries (Western Amazon basin) during the 1970 - 2012 period: a focus on the 2012 flood. J. Hydrometeorol. 14, 1000-1008. doi: 10.1175/JHM-D-12-0100.1

Espinoza, J. C., Ronchail, J., Lengaigne, M., Quispe, N., Silva, Y., Bettolli, M. L., et al. (2013b). Revisiting wintertime cold air intrusions at the East of the Andes: Propagating features from subtropical Argentina to Peruvian Amazon and relationship with large-scale circulation patterns. Clim. Dyn. 41, 1983-2002. doi: 10.1007/s00382-012-1639-y

Funk, C., Shukla, S., Thiaw, W. M., Rowland, J., Hoell, A., McNally, A., et al. (2019). Recognizing the famine early warning systems network: over 30 years of drought early warning science advances and partnerships acknowledge the German Red Cross for establishing and supporting the $\mathrm{FbF}$ mechanism and for the support of their staff in Peru. We are grateful to the reviewers for their constructive comments that contributed to improving the revised version of the manuscript. promoting global food security. Bull. Am. Meteorol. Soc. 100, 1011-1027. doi: 10.1175/BAMS-D-17-0233.1

Garreaud, R. (1999). Cold air incursions over subtropical and tropical south America: a numerical case study. Mon. Weather Rev. 127, 2823-28532. doi: $10.1175 / 1520-0493(1999) 127<2823:$ CAIOSA $>2$. $0 . \mathrm{CO} ; 2$

GRC (2017). Forecast-Based Financing a Policy Overview. GRC.

GRC (2020). Red Cross Red Crescent FbF Practitioner's Manual. GRC.

Gros, C., Bailey, M., Schwager, S., Hassan, A., Zingg, R., Uddin, M. M., et al. (2019). Household-level effects of providing forecast-based cash in anticipation of extreme weather events: quasi-experimental evidence from humanitarian interventions in the 2017 floods in Bangladesh. Int. J. Disaster Risk Reduct. 41:101275. doi: 10.1016/j.ijdrr.2019.101275

Gros, C., Easton-Calabria, E., Bailey, M., Dagys, K., de Perez, E.C., Sharavnyambuu, M., et al. (2021), The effectiveness of forecast-based humanitarian assistance in anticipation of extreme winters: a case study of vulnerable herders in Mongolia. Disasters. doi: 10.1111/disa.12467

Huggel, C., Caplan-Auerbach, J., and Wessels, R. (2008). Recent extreme avalanches: triggered by climate change? EOS Trans. Am. Geophys. Union 89 , 469-470. doi: 10.1029/2008EO470001

Hurley, J. V., Vuille, M., Hardy, D. R., Burns, S. J., and Thompson, L. G. (2015), Cold air incursions, $\delta 18 \mathrm{O}$ variability, and monsoon dynamics associated with snow days at Quelccaya Ice Cap, Peru. J. Geophys. Res. Atmos. 120, 7467-7487. doi: 10.1002/2015JD023323

IFRC (2003). Peru: Cold Wave-Information Bulletin $n^{\circ} 3$. IFRC.

IFRC (2008). Early Warning, Early Action An Evaluation of IFRC West and Central Africa Zone Flood Preparedness and Response, 2008. Available online at: https:// www.climatecentre.org/wp-content/uploads/EWEA-WCAZ-Evaluation.pdf

IFRC (2009). World Disasters Report 2009: Focus on Early Warning and Early Action. Geneva: International Federation of the Red Cross and Red Crescent Societies, 204. Available online at: www.ifrc.org/publicat/wdr2009/summaries. asp

IFRC (2013). Peru: Extreme Temperature (snowfall). IFRC.

IFRC (2018). Peru: Extreme Cold and Snowfall Early Action Protocol Summary. IFRC.

INEI (2019). Economia, sociedad y estadistica. INEI.

Jjemba, E. W., Mwebaze, B. K., Arrighi, J., de Perez, E. C., and Bailey, M. (2018). "Chapter 19 - Forecast-based financing and climate change adaptation: Uganda Makes history using science to prepare for floods," in Resilience: The Science of Adaptation to Climate Change, eds Z. Zommers and K. Alverson (Elsevier), 237-242. doi: 10.1016/B978-0-12-811891-7.00019-0

Koubi, V., Spilker, G., Schaffer, L., and Böhmelt, T. (2016). The role of environmental perceptions in migration decision-making: evidence from both migrants and non-migrants in five developing countries. Popul. Environ. 38, 134-163. doi: 10.1007/s11111-016-0258-7

Lopez, A., de Perez, E. C., Bazo, J., Suarez, P., van den Hurk, B., and van Aalst, M. (2020). Bridging forecast verification and humanitarian decisions: a valuation approach for setting up action-oriented early warnings. Weather Clim. Extrem. 27:100167. doi: 10.1016/j.wace.2018.03.006

MacLeod, D. A., Dankers, R., Graham, R., Guigma, K., Jenkins, L., Todd, M. C., et al. (2021). Drivers and subseasonal predictability of heavy rainfall in equatorial east Africa and relationship with flood risk. J. Hydrometeorol. 22, 887-903. doi: 10.1175/JHM-D-20-0211.1

Marengo, J. A., Nobre, C. A., and Culf, A. D. (1997). Climatic impacts of "friagens" in forested and deforested areas of the amazon basin. J. Appl. Meteorol. 36:1553. doi: 10.1175/1520-0450(1997)036<1553:CIOFIF >2.0.CO;2

Montes de Oca, I. (1995). Geografia y Clima de Bolivia (Geography and climate of Bolivia). Bull. Inst. Fr. Etud. Andines 24, 357-368. 
Oliver-Smith, A. (2014). "Climate change adaptation and disaster risk reduction in highland Peru," in Adapting to Climate Change (Berlin: Springer), 77-100. doi: 10.1007/978-94-017-8631-7_4

Otto, F. E., Philip, S., Kew, S., Li, S., King, A., and Cullen, H. (2018). Attributing high-impact extreme events across timescales-a case study of four different types of events. Clim. Change 149, 399-412. doi: 10.1007/s10584-018-2258-3

PCM (2019). Plan multisectorial ante heladas y friaje 2019-2021. PCM.

Ponce, C. (2020). Intra-seasonal climate variability and crop diversification strategies in the peruvian andes: a word of caution on the sustainability of adaptation to climate change. World Dev. 127:104740. doi: 10.1016/j.worlddev.2019.104740

Pradhan, B., Sharma, P., and Pradhan, P. K. (2019). Impact of Cold Wave on Vulnerable People of Tarai Region, Nepal, Climate Change and Global Warming, Ata Amini. IntechOpen, doi: 10.5772/intechopen.82201

Ronchail, J. (1989). Advecciones polares en Bolivia: caracterización de los efectos climáticos. Bull. Inst. 18:1.

Rosas, G., Gubler, S., Oria, C., Acun a, D., A’valos, G., Begert, M., et al. (2016). Toward implementing climate services in Peru-the project climandes. Clim. Serv. 4, 30-41. doi: 10.1016/j.cliser.2016.10.001

Sanchez, A. (2018). Early-Life Exposure to Weather Shocks and Human Capital Accumulation: Evidence from the Peruvian Highlands. Colorado: Young Lives.

Sperling, F., Validivia, C., Quiroz, R., Valdivia, R., Angulo, L., Seimon, A. (2008). Transitioning to Climate Resilient Development: Perspectives from Communities in Peru. Climate Change Series Environment Department Papers No. 115. Washington, DC: World Bank.

Stäubli, A., Nussbaumer, S. U., Allen, S. K., Huggel, C., Arguello, M., Costa, F., et al. (2018). "Analysis of weather- and climate-related disasters in mountain regions using different disaster databases," in Climate Change, Extreme Events and Disaster Risk Reduction. Sustainable Development Goals Series, eds S. Mal, R. Singh, and C. Huggel (Cham: Springer). doi: 10.1007/978-3-319-56469-2_2

Tall, A. (2010). Climate forecasting to serve communities in west Africa. Procedia Environ. Sci. 1, 421-431. doi: 10.1016/j.proenv.2010.09.030

Trasmonte, G., Chavez, R., Segura, B., and Rosales, J. L. (2008). Frost risks in the Mantaro river basin. Adv. Geosci. Eur. Geosci. Union 14, 265-270. doi: 10.5194/adgeo-14-265-2008

Conflict of Interest: The authors declare that the research was conducted in the absence of any commercial or financial relationships that could be construed as a potential conflict of interest.

Publisher's Note: All claims expressed in this article are solely those of the authors and do not necessarily represent those of their affiliated organizations, or those of the publisher, the editors and the reviewers. Any product that may be evaluated in this article, or claim that may be made by its manufacturer, is not guaranteed or endorsed by the publisher.

Copyright (๑) 2021 Bazo, de Perez, Jacome, Mantilla, Destrooper and Van Aalst. This is an open-access article distributed under the terms of the Creative Commons Attribution License (CC BY). The use, distribution or reproduction in other forums is permitted, provided the original author(s) and the copyright owner(s) are credited and that the original publication in this journal is cited, in accordance with accepted academic practice. No use, distribution or reproduction is permitted which does not comply with these terms. 